GANIT J. Bangladesh Math. Soc. (ISSN 1606-3694) 38 (2018) 73-83

DOI: https://doi.org/10.3329/ganit.v38i0.39787

\title{
HEAT-MASS TRANSFER OF NANOFLUID IN LID-DRIVEN ENCLOSURE UNDER THREE CONVECTIVE MODES
}

\author{
M.S. Rahman ${ }^{1 *}$, R. Nasrin ${ }^{2}$ and M.I. Hoque ${ }^{3}$ \\ ${ }^{1}$ M.Phil., Researcher, Department of Science \&Humanities (SH), MIST, Dhaka, \\ ${ }^{2}$ Associate Professor, Department of Mathematics, BUET, Dhaka-1000, Bangladesh, \\ ${ }^{3}$ Instructor Class 'B', Department of Science \& Humanities (SH), MIST, Dhaka, \\ ${ }^{*}$ Corresponding author: msr.rumc@gmail.com
}

Received 20.04.2018 Accepted 05.09.2018

\begin{abstract}
Heat is a form of energy which transfers between bodies which are kept under thermal interactions. When a temperature difference occurs between two bodies or a body with its surroundings, heat transfer occurs. Heat transfer occurs in three modes. Three modes of heat transfer are conduction, convection and radiation. Convection is a very important phenomenon in heat transfer applications and it occurs due to two different gradients, such as, temperature and concentration. This paper reports a numerical study on forced-mixed-natural convections within a lid-driven square enclosure, filled with a mixture of water and $2 \%$ concentrated $\mathrm{Cu}$ nanoparticles. It is assumed that the temperature difference driving the convection comes from the side moving walls, when both horizontal walls are kept insulated. In order to solve general coupled equations, a code based on the Galerkin's finite element method is used. To make clear the effect of using nanofluid on heat and mass transfers inside the enclosure, a wide range of the Richardson number, taken from 0.1 to 10 is studied. A fair degree of precision can be found between the present and previously published works. The phenomenon is analyzed through streamlines, isotherm and iso-concentration plots, with special attention to the Nusselt number and Sherwood number. The larger heat and mass transfer rates can be achieved with nanofluid than the base fluid for all conditions at Richardson number, $R i=0.1$ to 10 . It has been found that the heat and mass transfer rate increase approximately $6 \%$ for water with the increase of $R i=0.1$ to 10 , whereas these increase about $34 \%$ for nanofluid.
\end{abstract}

Keywords: Heat-mass transfer; convection; nanofluid; lid driven cavity.

\section{Introduction}

Heat and mass transfer are kinetic processes that may occur and be studied separately or jointly. Studying them apart is simpler, but both processes are modeled by similar mathematical equations in the case of diffusion and convection (there is no mass-transfer similarity to heat radiation), and it is thus more efficient to consider them jointly. Besides, heat and mass transfer must be jointly considered in some cases like evaporative cooling and ablation [1-2]. Heat-transfer problems arise in many industrial and environmental processes, particularly in energy utilization, thermal processing, and thermal control. Convection is a very important phenomenon in heat transfer applications and it occurs due to two different gradients, such as, temperature and concentration. The temperature and concentration gradients creates the buoyancy effects and hence the 
convection is called double diffusive convection. Convection is mass transfer due to the bulk motion of a fluid. For example, the flow of liquid water transports molecules or ions that are dissolved in the water. Similarly, the flow of air transports molecules present in air, including both concentrated species (e.g., oxygen and nitrogen) and dilute species (e.g., carbon dioxide).

Nanofluid is a new kind of heat transfer medium, containing nanoparticles (1-100 nm) which are uniformly and stably distributed in a base fluid. These distributed nanoparticles, generally a metal or metal oxide greatly enhance the thermal conductivity of the nanofluid, increases conduction and convection coefficients, allowing for more heat transfer [3-10].

Combined forced and natural convection is often seen in very-high-power-output devices where the forced convection is not enough to dissipate all of the heat necessary. At this point, combining natural convection with forced convection will often deliver the desired results. Examples of these processes are nuclear reactor technology and some aspects of electronic cooling. Kunznetsov and Sheremet [11] discussed on numerical simulation of double- diffusive conjugate natural convection in an enclosure whereas Oztop and Abu-Nada [12] investigated on natural convection in partially heated rectangular enclosures filled with nanofluids. Nikbhakti et al. [13] considered doublediffusive natural convection in a rectangular cavity with partially thermally active side walls. Mahapatra et al. [14] numerically studied effects of buoyancy ratio on double-diffusive natural convection in a lid-driven cavity.Forced convective heat transfer has many applications: geothermal engineering, solar-collectors, cold storage performance, thermal insulation of buildings, chemical reactors, electrical, microelectronic equipment's [15-16]. The Lid-driven cavity is a well-known benchmark problem for viscous incompressible fluid flow [17-18].

Therefore the present study different convective phenomena inside a square cavity using $\mathrm{Cu} / \mathrm{water}$ nanofluid is investigated. Necessary numerical studies are still required to monitor the variation of double diffusive system with economic and environmental considerations, which forms the basis of the motivation behind selecting the present study. The Richardson number is adjusted between 0.1 and 10 when the nanofluid volume fraction is fixed at 0.02 . The streamlines, the isotherm and the iso-concentration patterns for various values of the Richardson number are observed.

\section{Geometrical Modeling}

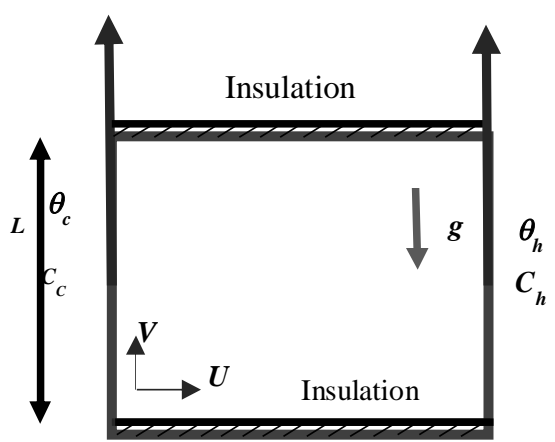

Fig. 1: Schematic geometry and boundary condition 
Consider a steady-state two-dimensional square cavity of length $L$ as shown in Figure 1 . Top and bottom wall are insulated, and impermeable to mass transfer and the left and right wall are kept at constant temperature and concentration. The right wall is kept at high temperature $\left(\theta_{h}\right)$ and concentration $\left(C_{h}\right)$, whereas, the left wall is at low temperature $\left(\theta_{c}\right)$ and concentration $\left(C_{c}\right)$. the forced convection is provided by the movement of the left and right walls with constant velocity $V_{0}$ in $\mathrm{y}+$ direction. The Cavity is filled with an incompressible Newtonian fluid. Also the properties of the fluid such as thermal conductivity and diffusivity are kept at constant except for density.

\section{Mathematical Model}

The prevailing continuity, momentum and energy equations for the problem of viscous incompressible flow and the temperature distribution with the Boussinesq approximations inside the enclosure can be the presented in non-dimensional form as follows:

Continuity Equation:

$$
\frac{\partial U}{\partial X}+\frac{\partial V}{\partial Y}=0
$$

X Momentum Equation:

$$
U \frac{\partial U}{\partial X}+V \frac{\partial U}{\partial Y}=-\frac{\rho_{f}}{\rho_{n f}} \frac{\partial P}{\partial X}+\frac{v_{n f} \operatorname{Pr}}{v_{f}}\left(\frac{\partial^{2} U}{\partial X^{2}}+\frac{\partial^{2} U}{\partial Y^{2}}\right)
$$

Y Momentum Equation:

$$
U \frac{\partial V}{\partial X}+V \frac{\partial V}{\partial Y}=-\frac{\rho_{f}}{\rho_{n f}} \frac{\partial P}{\partial Y}+\frac{v_{n f} \operatorname{Pr}}{v_{f}}\left(\frac{\partial^{2} V}{\partial X^{2}}+\frac{\partial^{2} V}{\partial Y^{2}}\right)+\left(\frac{\beta_{n f}}{\beta_{f}}\right) \operatorname{Ri}(\theta-N r C)
$$

Energy Conservation Equation

$$
U \frac{\partial \theta}{\partial X}+V \frac{\partial \theta}{\partial Y}=\frac{\alpha_{n f}}{\alpha_{f}} \frac{1}{\operatorname{Pr}}\left(\frac{\partial^{2} \theta}{\partial X^{2}}+\frac{\partial^{2} \theta}{\partial Y^{2}}\right)+D f\left(\frac{\partial^{2} C}{\partial X^{2}}+\frac{\partial^{2} C}{\partial Y^{2}}\right)
$$

Concentration Conservation Equation:

$$
U \frac{\partial C}{\partial X}+V \frac{\partial C}{\partial Y}=\frac{D_{n f}}{D_{f}} \frac{1}{S c}\left(\frac{\partial^{2} C}{\partial X^{2}}+\frac{\partial^{2} C}{\partial Y^{2}}\right)+S r\left(\frac{\partial^{2} \theta}{\partial X^{2}}+\frac{\partial^{2} \theta}{\partial Y^{2}}\right)
$$

The non- dimensional Parameters are defined in the following forms,

$X=\frac{x}{L}, Y=\frac{y}{L}, U=\frac{u}{V_{0}}, V=\frac{v}{V_{0}}, P=\frac{p}{\rho_{n f} V_{0}^{2}}, \theta=\frac{T-T_{c}}{T_{h}-T_{c}}, C=\frac{c-c_{c}}{c_{h}-c_{c}}$, with $T_{h}>T_{c}$ and $C_{h}>C_{c}$.

Here $\operatorname{Pr}=v_{f} / \alpha_{f}$ be the Prandtl number, $R i=R a / \operatorname{Re}^{2}$ be the Richardson number, $R a=g \beta_{f}\left(T_{h}-T_{c}\right) L^{3} / v_{f} \alpha_{f}$ be the Rayleigh number, $R a_{T}=g \beta_{T f}\left(T_{h}-T_{c}\right) L^{3} / v_{f} \alpha_{f}$ be the thermal Rayleigh number, $R a_{c}=g \beta_{c f}\left(T_{h}-T_{c}\right) L^{3} / v_{f} \alpha_{f}$ be the solutal Rayleigh number, $N r=R a_{c} / R a_{T}$ 
be the buoyancy ratio, $S c=(v / D)_{f}$ be the Schmidt number, $D f=\left(\frac{D}{v}\right)_{f} \frac{\kappa_{T f}\left(C_{h}-C_{c}\right)}{C_{s} C_{p}\left(T_{h}-T_{c}\right)}$ be the Dufour coefficient and $S r=\left(\frac{D}{v}\right)_{f} \frac{\kappa_{T f}\left(T_{h}-T_{c}\right)}{T_{m}\left(C_{h}-C_{c}\right)}$ be the Soret coefficient.

Thermo physical Properties of Cu-water nanofluid like effective density, thermal diffusivity, heat capacities and thermal expansion co efficient of nanofluid are given as follows:

The effective density $\rho_{n f}=(1-\varphi) \rho_{f}+\varphi \rho_{p}$,

The effective heat capacity $\alpha_{n f}=k_{n f} /\left(\rho c_{p}\right)_{n f}$

The effective thermal expansion co efficient $\left(\rho c_{p}\right)_{n f}=(1-\varphi)\left(\rho c_{p}\right)_{f}+\varphi\left(\rho c_{p}\right)_{n}$

The effective thermal diffusivity $(\rho \beta)_{n f}=(1-\varphi)(\rho \beta)_{f}+\varphi(\rho \beta)_{n}$

According to the Brinkmann model [19], the effective dynamic viscosity of the nanofluid is agreed by $\mu_{n f}=\frac{\mu_{f}}{(1-\varphi)^{2.5}}$

The Thermal conductivity of the nanofluid is modeled by Maxwell- Garnett model [20] as

$$
\frac{k_{n f}}{k_{f}}=\frac{k_{p}+2 k_{f}-2 \varphi\left(k_{f}-k_{p}\right)}{k_{p}+2 k_{f}+\varphi\left(k_{f}-k_{p}\right)}
$$

The boundary conditions for the present problem are specified as :

\begin{tabular}{lllll}
\hline Boundary conditions & $T$ & $C$ & $U$ & $V$ \\
\hline Left wall; $\mathrm{X}=0 ; 0 \leq \mathrm{Y} \leq 1$ & $\theta_{c}$ & $C_{c}$ & 0 & 1 \\
Right wall; $\mathrm{X}=\mathrm{L} ; 0 \leq \mathrm{Y} \leq 1$ & $\theta_{h}$ & $C_{h}$ & 0 & 1 \\
Top wall; $0 \leq \mathrm{X} \leq 1 ; \mathrm{Y}=\mathrm{L} ;$ & $\frac{\partial \theta}{\partial y}=0$ & $\frac{\partial C}{\partial y}=0$ & 0 & 0 \\
Bottom wall; $0 \leq \mathrm{X} \leq 1 ; \mathrm{Y}=0 ;$ & $\frac{\partial \theta}{\partial y}=0$ & $\frac{\partial C}{\partial y}=0$ & 0 & 0 \\
\hline
\end{tabular}

The average Nusselt number $(\mathrm{Nu})$ at the heated wall is calculated by integrating the local Nusselt number is given by $N u=\frac{1}{L} \int_{0}^{1} \overline{N u} d Y$.

The local Nusselt number is defined as $\overline{N u}=-\frac{k_{n f}}{k_{f}} \frac{\partial \theta}{\partial X}$.

Similarly, the average Sherwood number $(S h)$ at the heated wall is calculated by $S h=-\frac{k_{n f}}{k_{f}} \frac{1}{L} \int_{0}^{1} \frac{\partial C}{\partial X} d Y$. 


\section{Numerical Implementation}

The Galerkin's finite element method [21] is used to solve the non-dimensional governing equations along with boundary conditions for the considered problem. The equation of continuity has been used as a constraint due to mass conservation and this restriction may be used to find the pressure distribution. The finite element method is used to solve the Eqs. (2) - (5), where the pressure $P$ is eliminated by a constraint. The continuity equation (1) is automatically fulfilled for large values of this penalty constraint. Then the velocity components $(U, V)$, temperature $(\theta)$ and concentration $(C)$ are expanded using a basis set. The finite element technique yields the subsequent nonlinear residual equations. Three points Gaussian quadrature is used to evaluate the integrals in these equations. The non-linear residual equations are solved using Newton-Raphson method to determine the coefficients of the expansions. The convergence of solutions is assumed when the relative error for each variable between consecutive iterations is recorded below the convergence criterion $\varepsilon$ such that, $\left|\Psi^{n+1}-\Psi^{n}\right| \leq 10^{-6}$ where $n$ is the number of iteration and $\Psi$ is a function of $U, V, \theta$ and $C$.

\subsection{Mesh Generation}

The Finite element meshing of the computational Domain is displayed by the figure 2. Extra fine meshing is chosen for this geometry

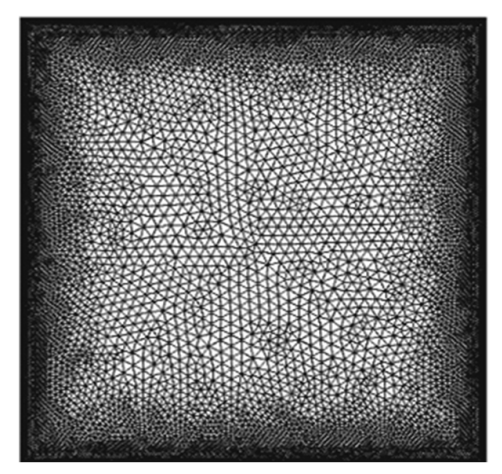

Fig. 2: Mesh generation of the 2D domain

\subsection{Grid check}

A grid-independent check has been performed at $R i=0.1, \operatorname{Pr}=5.8, D f=2, S c=5, S r=5, N r=1$. Five different non-uniform grid systems have been checked with the number of elements: 1,496; 2,$518 ; 6,614 ; 17,050$ and 26,368. Heat and mass transfer rate for different mesh for water-Cu nanofluid $(\varphi=2 \%)$ has been considered as supervising parameter. It has been noticed that the fifth and sixth column of Table 1 that there is no considerable alternation in the value of mean Nusselt and Sherwood number. Thus extra fine mesh with 17,050 elements has been chosen for numerical simulation. 
Table 1: Grid Sensitivity Check at $R i=0.1, P r=5.8, D f=2, S c=5, S r=5, N r=1$

\begin{tabular}{|l|c|c|c|c|c|}
\hline Mesh type & Normal & Fine & Finer & Extra fine & Extremely fine \\
\hline Elements & 1,496 & 2,518 & 6,614 & $\mathbf{1 7 , 0 5 0}$ & 26,368 \\
\hline $\mathrm{Nu}$ & 3.8563 & 4.3819 & 5.03668 & $\mathbf{5 . 7 2 3 5}$ & 5.7247 \\
\hline $\mathrm{Sh}$ & 1.0085 & 1.02917 & 1.02917 & $\mathbf{1 . 0 6 1 0}$ & 1.1034 \\
\hline Time $(\mathrm{s})$ & 29 & 46 & 114 & $\mathbf{1 7 9}$ & 346 \\
\hline
\end{tabular}

\subsection{Thermo-physical properties}

The thermo-physical properties of the base fluid and the nanoparticles are taken from Nasrin and Alim [15]

Table 2: Thermo-physical properties of water and $\mathrm{Cu}$ nanoparticle

\begin{tabular}{|l|c|c|}
\hline Physical Properties & Fluid phase (water) & $\mathrm{Cu}$ \\
\hline$C_{p}\left[\mathrm{JKg}^{-1} \mathrm{~K}^{-1}\right]$ & 4179 & 385 \\
\hline$\rho\left[\mathrm{kgm}^{-3}\right]$ & 997.1 & 8933 \\
\hline$k\left[\mathrm{Wm}^{-1} \mathrm{~K}^{-1}\right]$ & 0.61 & 401 \\
\hline$\alpha \times 10^{7}\left[\mathrm{~m}^{2} \mathrm{~s}^{-1}\right]$ & 1.47 & 1163.1 \\
\hline$\beta \times 10^{5}\left[\mathrm{~K}^{-1}\right]$ & 21 & 1.67 \\
\hline
\end{tabular}

\subsection{Code Validation}

The present code results for average Nusselt $(\mathrm{Nu})$ numbers with the variation of volume fraction $(\varphi)$ using $R i=10, \operatorname{Pr}=5.8, D f=2, S c=5, N r=1, R a=10^{4}$ with the graphical demonstration of Oztop and Abu-Nada [12]. The code validation has been shown in the Table 3 including relative error as well as figure 3 . The present code results agree very well with that of [12].

Table 3: Code validation with Oztop and Abu-Nada [12]

\begin{tabular}{|c|c|c|c|}
\hline $\boldsymbol{\varphi}$ & Present result $\boldsymbol{N u}$ & Oztop and Abu-Nada [12] & Relative error (\%) \\
\hline 0 & 3.992 & 3.983 & 0.21 \\
\hline 0.05 & 4.286 & 4.271 & 0.39 \\
\hline 0.1 & 2.207 & 2.203 & 0.87 \\
\hline 0.15 & 2.291 & 2.283 & 0.23 \\
\hline 0.2 & 2.383 & 2.363 & 0.36 \\
\hline
\end{tabular}

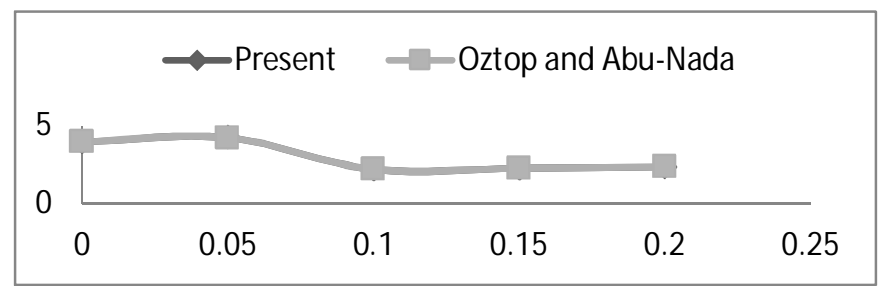

Fig. 3: Code validation with Oztop and Abu-Nada [12] 


\section{Result and Discussion}

Numerical investigation has been conducted to determine the performance of three convections on heat and mass transfer rate inside a lid-driven cavity using water-Cu nanofluid. The effect of Richardson number $(\mathrm{Ri})$ has been carried out. Average rate of heat and mass transfer have also been calculated at the heated and concentrated wall. The results have been discussed in different sections as follows:

\subsection{Effect of convection on streamlines}

The effects of three convection mode inside the square cavity filled with copper-water nanofluid has been investigated. Richardson number represent the relative comparison of natural and forced convection. The natural convection is negligible when $R i<0.1$, forced convection is negligible when $R i>10$, and neither is negligible when $0.1<R i<10$. The Richardson number is adjusted between 0.1 and 10 when the nanofluid volume fraction is fixed at 0.02 . The streamline, isotherm and iso concentration for various values of the Richardson number are presented in the figure 4-6.

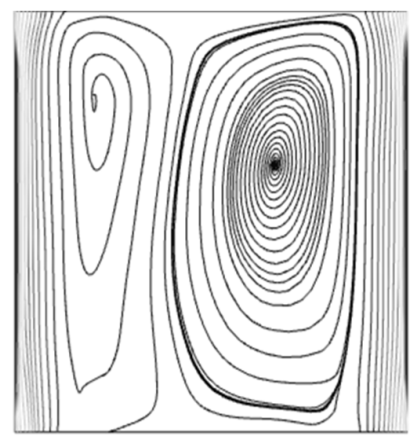

$R i=0.1$

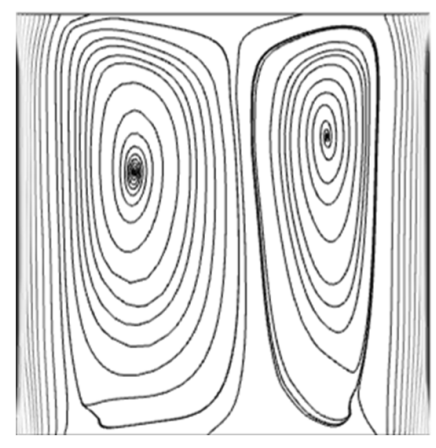

$R i=1$

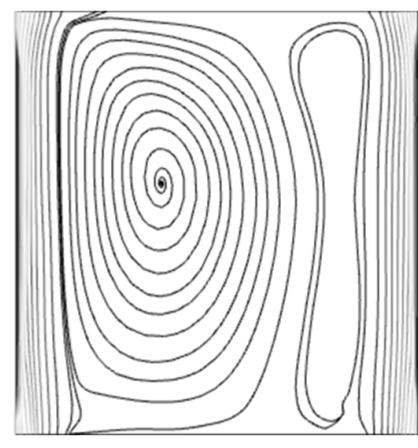

$R i=10$

Fig. 4: Streamlines for $\operatorname{Pr}=5.8, D f=2, S r=5, S c=5, \varphi=0.02$

\subsection{Effect of convection on isotherms}

In the case of a dominant forced convection $(R i=0.1)$, the left and right regions, the flow of water/Cu nanofluid seems in streamline and isotherm to be more compact than at the middle. The effects on streamlines, the flow patterns develop stronger and dominant from left wall to right wall. Here in two streamline, right streamlines flowing in counter clockwise direction with hot fluid whereas the left streamlines in the clockwise direction with cold fluid is observed. At $R i=0.1$ observing left and right wall flow of water/copper nanofluid, it seems that right wall flow dominant to the left wall flow, whereas increase of $R i$ to 1 (mixed convection) and 10 (natural convection) left wall flow gradually dominant to right wall flow. It is observed the same types of changes in isotherm graph. 


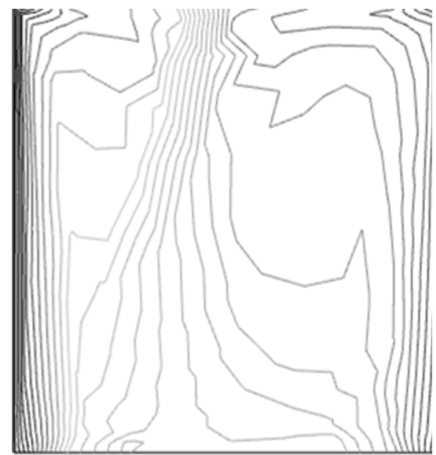

$R i=0.1$

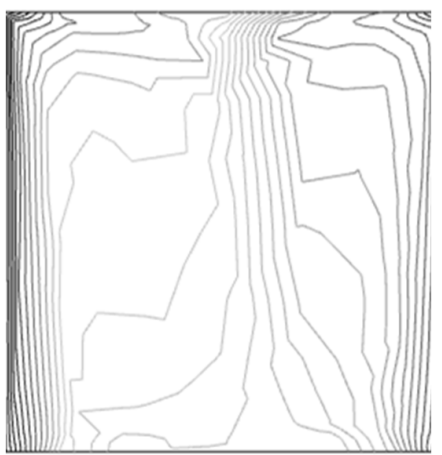

$R i=1$

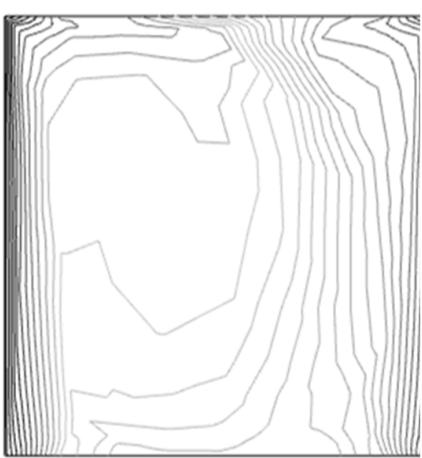

$R i=10$

Fig. 5: Isotherm for $\operatorname{Pr}=5.8, D f=2, S r=5, S c=5, \varphi=0.02$

\subsection{Effect of convection on iso-concentration}

With mixed convection $(R i=1)$ of water/copper nanofluid, it is observed that a combined effect of the translational motion of the active walls. Unlike the streamlines, where the same fluid motion is observed, it can be seen from the isotherms that the mixed convection mode of heat transfer leads to the decrease of the thermal boundary layers thickness to be more compact near the active walls.

However for free convective mode $(R i=10)$, the hot water/Cu nanofluid remains confined near hot wall when the cold nanofluid near the cold wall and the flow observe at the right half of the cavity whereas at the middle of left half it is empty. Observing the changes of $R i$ from 0.1 to 10 on isoconcentration figure the flow on top right and bottom right slightly drift to left. The effect of isoconcentration as observed in the given result that there is no significant differences. The concentration contours on the left and right side walls shows that mass distribution occurs only near the vertical walls.

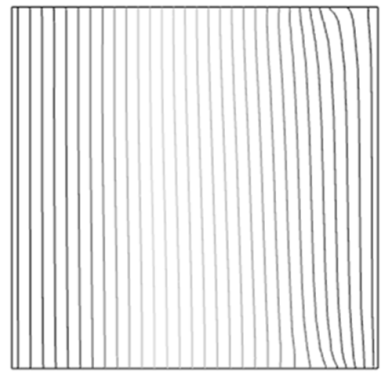

$R i=0.1$

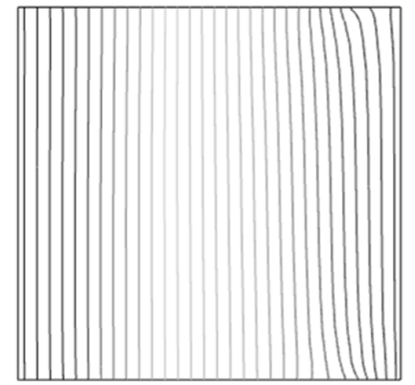

$$
R i=1
$$

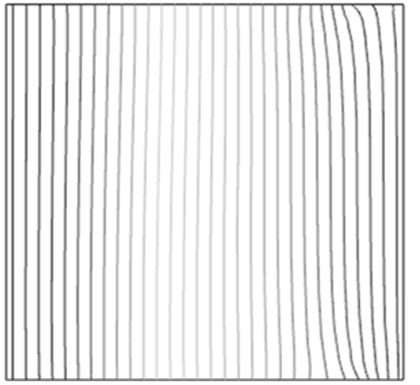

$R i=10$

Fig. 6: Iso-concentration at $\operatorname{Pr}=5.8, D f=2, S r=5, S c=5, \varphi=0.02$

\subsection{Average Nusselt and Sherwood Number}

Figures 7 and 8 display the average Nusselt number $(\mathrm{Nu})$ and Sherwood number $(\mathrm{Sh})$ with $\mathrm{Ri}$. These figures show that the rate of heat transfer and mass transfer rises monotonically after the use of $\mathrm{Cu}$-water nanofluids then clear water. That is in comparison of water, it is clear that, due to use 
of nanoparticle the heat and mass transfer rate increases. As increasing $R i$ from 0.1 to 1 , it is found that heat and mass transfer rate increase about $6 \%$ in the case of base fluid and around $34 \%$ in nanofluid . The difference of changes reduce after increasing $R i=1$ to 10 .

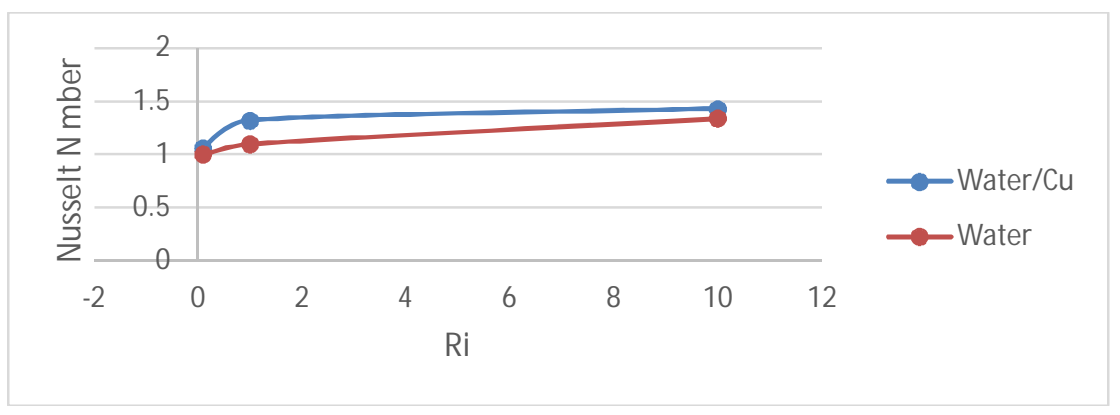

Fig. 7: Average Nusselt number for different $R i$

The effect of the water/Cu nanofluid with compared to clear water on the heat and mass transfer is reflected in the mean Nusselt number and Sherwood number variations for different convective modes. Heat and mass transfer increase for all convective mo des by using $2 \%$ concentrated water/Cu nanofluid than that of water.

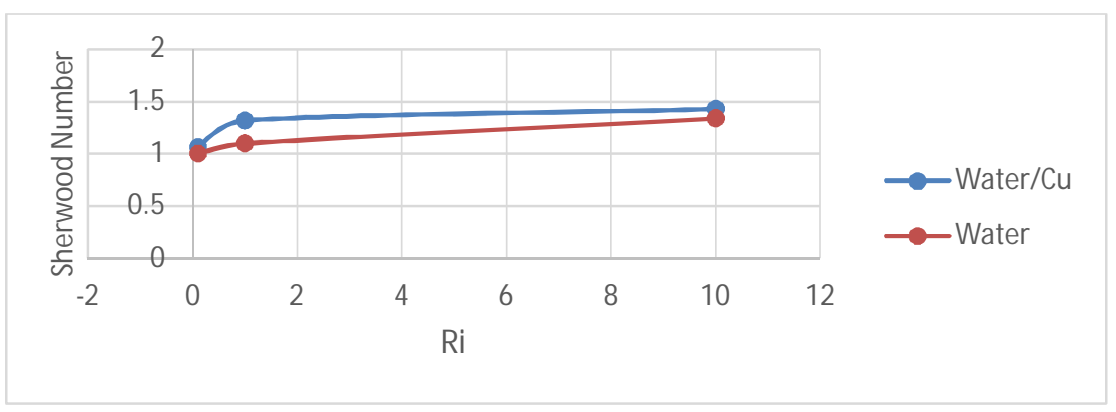

Fig. 8: Average Sherwood number for different $R i$

\section{Conclusion}

Taking into account the effects of the forced-mixed-natural convections using $2 \%$ concentrated water/copper nanofluid as well as base fluid (water), the results may resume as follows:

$\Rightarrow \quad$ Significant effects of different convective modes are observed on velocity, temperature and concentration distributions inside a lid-driven cavity filled water/Cu nanofluid.

$\Rightarrow$ Increasing rates of heat-mass transfer are found against increasing values of Richardson number.

$\Rightarrow$ Heat and mass transfer rate increase about $34 \%$ by using nanofluid due to changing convection procedure from forced to free.

$\Rightarrow$ Using water/Cu nanofluid as heat transferring fluid inside enclosure, rates of heat-mass transfer become higher than that of base fluid. 


\section{REFERENCES}

[1] Al- Amiri, A.M., Khanafer, K,M,. Pop, I, "Numerical simulation of combined thermal and mass transport in a square lid-driven cavity", Int. J. Therm. Sci., 46, (2007), pp 662-671.

[2] Nasrin R., "Heat-Mass Transfer in a tubular chemical reactor", Int. J. of Energy Sci. and Engg., 1, 2, (2015), pp 49-59.

[3] Nasrin R., Alim M.A. and Ahmed S.R., "Comparative study between 2D and3D modeling of nanofluid filled flat plate solar collector", Int. J. of Heat \& Tech., 34, 3, (2016), pp 527-536.

[4] Nasrin R., Alim M.A. and Hasanuzzaman M., "Assisted convective heat transfer and entropy generation inside a tilted solar collector filled nanofluid", J. of Naval Arch. and Marine Engg., 13, 2, (2016), pp. 135-150.

[5] Nasrin R., Parvin S. and Alim M.A., "Buoyant flow of nanofluid for heat-mass transfer through a thin layer" Mech. Engg. Res. J., 1, 9, (2013), pp. 7-12.

[6] Sreelakshmy K.R, Nai Aswathy S., Vidhya K.K, Saranya T.R, Sreeja C.N., "An overview of recent nanofluid research", Int. Res. J. Pharma., 5, 4, (2014), pp. 239-243.

[7] Ahmed K.F.U. and Nasrin R., "Numerical study of convective flow in a prismatic cavity using waterbased nanofluids", Int. J. of Chem. Engg. and Ana. Sci., 1, 2, (2016), pp 93-100.

[8] Parvin S., Nasrin R. and Alim M.A., "Effect of solid volume fraction on forced convective flow of nanofluid through direct absorption solar collector", Appl. and Appl. Maths.: An Int. J., Special Issue, 2, (2016), pp 9-21.

[9] Sreedevi P., Sudarsana Reddy P., Rao K.V.S.N., and Chamkha A.J., "Heat and mass transfer flow over a vertical cone through nanofluid saturated porous medium under convective boundary condition suction/injection", J. Nanofluids, 6, (2017), pp 478-486.

[10] Zargartalebi M, Azaiez J, "Heat transfer analysis of nanofluid based microchannel heat sink", Int. J. of Heat and Mass Transfer, 127, Part B, (2018), pp. 1233-1242.

[11] Kunznetsov G.V., Sheremet M.A., "A numerical simulation of double- diffusive conjugate natural convection in an enclosure", Int, J. Thermal Sci., 50, (2011), pp 1878-1886

[12] Oztop H.F., Abu-Nada, E., "Numerical study of natural convection in partially heated rectangular enclosures filled with nanofluids", Int. J. of Heat and Fluid Flow, 29, (2008), pp.1326-1336.

[13] Nikbhakti R., Asghar B, Rahimi, "Double-diffusive natural convection in a rectangular cavity with partially thermally active side walls", J. of the Taiwan Inst. of Chem. Engineers, 43, (2012), pp 535-541.

[14] Mahapatra T.R., Pal D., Mondol S., "Effects of buoyancy ratio on double-diffusive natural convection in a lid -driven cavity", Int. J. of Heat and Mass Trans., 57, (2013), pp771-785

[15] Nasrin R. and Alim M.A., Finite element simulation of forced convection in a flat plate solar collector: Influence of nanofluid with double nanoparticles, J. of Appl. Fluid Mech., 7, 3, (2014), pp.543-557.

[16] Willn J.B., VennerC.H., "An experimental study of forced convective heat transfer from smooth, solid spheres", International Journal of Heat and Mass Transfer, 109, (2017), pp. 1059-1067

[17] Teamah M.A., Sorour M.M., El-Maghlany W.M, Afifi A., "Numerical simulation of double diffusive laminar mixed convective in shallow inclined cavities with moving lid", Alexandria Engg. J., 52, 3, (2013), pp. 227-239.

[18] Chen C.L., Cheng C.H, "Numerical Simulation of periodic mixed convection heat transfer in a rectangular cavity with a vibrating lid", App. Thermal Engg., 29, (2009), pp 2855-2862.

[19] Brinkman H.C., The viscosity of concentrated suspensions and solution, J. Chem. Phys., 20, (1952), pp. 571-581.

[20] Maxwell-Garnett J.C., Colours in metal glasses and in metallic films, Philos. Trans. Roy. Soc. A, 203 (1904), pp. 385-420.

[21] Reddy J.N., Gartling D.K., The Finite Element Method in Heat Transfer and Fluid Dynamics, CRC Press, Inc., Boca Raton, Florida, 1994. 


\section{Nomenclature}

$\begin{array}{cll}\text { Symbol } & \text { Meaning } & \text { Unit } \\ c & \text { Concentration } & {\left[\mathrm{Kgm}^{-3}\right]} \\ C & \text { Concentration } & \text { Dimensionless } \\ C_{p} & \text { Specific Heat } & {\left[\mathrm{JKg}^{-1} \mathrm{~K}^{-1}\right]} \\ C s & \text { Concentration susceptibility } & {\left[\mathrm{m}^{-1} \mathrm{Kg}^{-1}\right]} \\ D & \text { Solutal diffusivity } & {\left[\mathrm{m}^{2} \mathrm{~s}^{-1}\right]} \\ D f & \text { Dufour coefficient } & \text { Dimensionless } \\ G & \text { Gravitational acceleration } & {\left[\mathrm{ms}^{-2}\right]} \\ K & \text { Thermal conductivity } & {\left[\mathrm{Wm}^{-1} \mathrm{~K}^{-1}\right]} \\ L & \text { Length of side } & {\left[\mathrm{m}^{-1}\right.} \\ N r & \text { Buoyancy Ratio number } & \text { Dimensionless } \\ N u & \text { Nusselt Number } & \text { Dimensionless } \\ P & \text { Pressure } & \text { Dimensionless } \\ P r & \text { Prandtl Number } & \text { Dimensionless } \\ R a & \text { Rayleigh Number } & \text { Dimensionless } \\ R a_{c} & \text { Solutal Rayleigh number } & \text { Dimensionless } \\ R a_{T} & \text { Thermal Rayleigh number } & \text { Dimensionless } \\ R e & \text { Reynolds Number } & \text { Dimensionless } \\ R i & \text { Richardson Number } & \text { Dimensionless } \\ S c & \text { Schmidt Number } & \text { Dimensionless } \\ S r & \text { Soret coefficient } & \text { Dimensionless } \\ T & \text { Temperature } & {[\mathrm{k}]} \\ u, v & \text { Velocity along } x \text { and } y \text { direction } & {[\text { ms }} \\ U, V & \text { Velocity component } & \text { Dimensionless } \\ x, y & \text { Cartesian coordinate } & {[\mathrm{m}]} \\ X, Y & \text { Coordinates } & \text { Dimensionless } \\ & & \end{array}$

\section{Greek Letters}

$\begin{array}{cll}\text { Symbol } & \text { Meaning } & \text { Unit } \\ \alpha & \text { Thermal diffusivity } & {\left[\mathrm{m}^{2} \mathrm{~s}^{-1}\right]} \\ \beta & \text { Thermal Expansion } & {\left[\mathrm{K}^{-1}\right]} \\ & \text { Coefficient } & \\ \theta & \text { Temperature } & \text { Dimensionless } \\ \mu & \text { Dynamic viscosity } & {\left[\mathrm{Nsm}^{-2}\right]} \\ v & \text { Kinematic Viscosity } & {\left[\mathrm{m}^{2} \mathrm{~s}^{-1}\right]} \\ \rho & \text { Density } & {\left[\mathrm{kgm}^{-3}\right]} \\ \varphi & \text { Solid volume fraction } & {[\%]}\end{array}$

\section{Subscripts}

$\begin{array}{ll}c & \text { Cold } \\ f & \text { Fluid } \\ h & \text { Hot } \\ n f & \text { Nanofluid } \\ s & \text { Solid particle }\end{array}$

